\title{
A Structural Relationship among Growth Mindset, Academic Grit, and Academic Burnout as Perceived by Korean High School Students
}

\author{
Kyu Tae Kim \\ Department of Education, Keimyung University, South Korea
}

Received May 20, 2020; Revised July 8, 2020; Accepted July 20, 2020

\section{Cite This Paper in the following Citation Styles}

(a): [1] Kyu Tae Kim , "A Structural Relationship among Growth Mindset, Academic Grit, and Academic Burnout as Perceived by Korean High School Students," Universal Journal of Educational Research, Vol. 8, No. 9, pp. 4009 - 4018, 2020. DOI: 10.13189/ujer.2020.080926.

(b): Kyu Tae Kim (2020). A Structural Relationship among Growth Mindset, Academic Grit, and Academic Burnout as Perceived by Korean High School Students. Universal Journal of Educational Research, 8(9), 4009 - 4018. DOI: 10.13189/ujer.2020.080926.

Copyright $\subseteq 2020$ by authors, all rights reserved. Authors agree that this article remains permanently open access under the terms of the Creative Commons Attribution License 4.0 International License

\begin{abstract}
This study explored the structural relationship among growth mindset, academic grit, and academic burnout. This study investigated the impact of Korean high school students' growth mindset on their academic burnout. Also, it is this study's contention that the effect of growth mindset on academic burnout can be changed when academic grit as a persistent enthusiasm and effort in their studies are mediating. The sample of this study comprised 573 Korean high school students (aged 17 years) in 2018. This study was designed as correlational research, and data analysis was conducted mainly using structural equation modelling. This study found that growth mindset may act as a diminishing factor for academic burnout. In addition, this study found that academic grit negatively mediated the relationship between growth mindset and academic burnout, implying that academic grit can play a determinant role as a positive psychological variable that could alleviate or prevent academic burnout. Thus, programming and counseling oriented toward fostering academic grit and coupled with growth mindset should be provided to lessen or prevent academic burnout. This study fills a void in the literature on academic grit and on growth mindset in targeting academic burnout among high school students preparing for college entrance examinations.
\end{abstract}

Keywords Growth Mindset, Grit, Academic Burnout, High School Students

\section{Introduction}

Korea is a country that passionately places high expectations on its children's educational outcomes, as is evident in the nationwide enthusiasm for the day of the university entrance examination. Every year in the middle of November, students who expect to graduate from high school and those who have recently graduated take the national college entrance test, an all-day examination—from 8:00 to 17:00—of their knowledge of Korean, Math, English, Science, Social studies, and Korean history. This is the one single test for which high school students have prepared for three years, from entering high school to graduation. It is also the only opportunity to advance to college. Students who earn a low score on this exam will not be able to enter top-ranked colleges and will need to retake the exam the following year. For the convenience of test takers nationwide, government offices, banks, and businesses postpone their work hours from 9:00 am to 10:00 am. In addition, with the English listening test from 1:05 pm to 1:40 pm, takeoff and landing of all aircraft in Korea is prohibited so as not to interfere with radio broadcasting. When the test concludes that evening, students are exposed to the difficulty level of each subject along with the test questions and answers in 
the broadcasting stations, newspapers or social media. The next day, test takers tentatively estimate their test scores before they officially receive their test score in early December, anticipating the passing score of the universities that they want to enter. The media also report the scores expected by prestigious universities in anticipation of scorers of $95 \%$ or higher.

In 2016, college enrollment in Korea accounted for 73\% of 19-year-old tertiary education registration, which is more than double the Organisation for Economic Co-operation and Development (OECD) average of 34\% (2018). This tertiary enrollment rate owes to the quality both of the general public high school education offered to adolescents and of the private tutoring that parents provide for their children. Children have regular classes from 8 am to $4 \mathrm{pm}$, and many students study for 3 to 4 hours more in their school's library or school classrooms until $10 \mathrm{pm}$. Additionally, the Korea Statistical Office (2019) reported that $58.5 \%$ of high school students in 2018 participated in private tutoring or classrooms in cram schools (private institutions offering additional study) for a weekly average of 5.3 hours and cost a per-student monthly average of USD 321 dollars for tutoring. This enthusiasm and investment in education has resulted in Korea's excellent performance in the OECD's Program for International Student Assessment (PISA), which tests 15-year-old students worldwide in reading, mathematics, and science every three years. Korea scored 517 points in reading, 524 points in mathematics, and 516 points in science, which is higher than the OECD average of 493 in reading, 490 in mathematics, and 493 science (OECD 2015).

According to the Korea Statistical Office (2018), 51.8\% of Korean high school students in 2018 were stressed by school life, and $27.1 \%$ were experiencing depression. Fifty-eight percent of high school students reported being satisfied with school life. The situation is similar to the results of the OECD Wellbeing Survey (2017), on which Korean students scored 0.1 in the academic index-a score higher than the OECD average of .01; the life satisfaction level was 6.4 on the 10-point scale, which is lower than the OECD average of 7.3. The reason is that $47.3 \%$ were worried about and felt burdened by the university entrance examination as well as heavy academic workloads throughout high school.

The Korea Statistical Office (2018) reported that 63.6\% of high school students had their future career and life goals, but $36.4 \%$ of them did not feel optimistic about their future careers. Korean high school students tend to give up on academic subjects they are learning because of their lack of interest in learning and their low achievement (Lee and Shin 2018). To illustrate, there is a Korean educational slang term Supoja, which is used in reference to high school students who have given up studying math owing to low interest and negative mindset in mathematics. The 2012 Program for International Student Assessment (OECD 2014) shows that Korean students had the lowest scores in terms of self-efficacy and interest in mathematics. They were also the lowest among countries in the interest and enthusiasm of science investigated through the PISA in 2015 (OECD 2017).

Although Korean students obtain higher PISA scores, they have lower academic interest and engagement as well as unclear and unsafe future careers and college admission (Lee and Shin 2018; Suh 2018). As a result, it is likely that they have a negative attitude or altogether abandon their study as well as feel incompetent, exhausted, and meaningless owing to low confidence in and negative beliefs about their academic aptitude and performance. In the meantime, other Korean students with higher ambition and optimism may be dedicated to future career and success in preparing for a difficult college entrance exam with a persistent passion and effort as well as with positive beliefs and expectations, even though they feel incompetent or exhausted and near burn out.

This study explored the structural relationship among growth mindset, academic grit, and academic burnout. This study investigated the impact of Korean high school students' growth mindset on their academic burnout. Also, it is this study's contention that the effect of growth mindset on academic burnout can be changed when academic grit as a persistent enthusiasm and effort in their studies are mediating.

\section{Theoretical Background and Hypotheses}

Mindset refers to a belief or thought concerning one's own intelligence and ability (Dweck 2006). That is, it is a way of thinking that academic performance can or cannot be changed depending on one's own inborn ability and present effort. According to Dweck (2009), mindset is classified into fixed mindset and growth mindset. A fixed mindset is a belief or thought tendency that students' intelligence or aptitude is inherently decided and cannot be changed no matter how hard students study. Meanwhile, a growth mindset indicates a belief that students believe their own intelligence or ability can be improved at any time through persistent effort (Blackwell, Trzesniewski, and Dweck 2007). Students with a fixed mindset not only have weak intrinsic motivation and low self-efficacy but also often experience academic incompetence and goal loss. However, a growth mindset allows students to set long-term goals and have the needed confidence to improve their academic achievement in spite of academic challenges and failures (Dweck 2006; McClendon, Neugebauer, and King 2017).

Academic burnout is a term used by Korean scholars to apply the burnout phenomenon to academic situations (Lee and Cho 2013; Lee, Lee, and Lee 2009; Suh 2018). Sulea, Beek, Sarbescu, Virga, and Schaufeli (2015) pointed out that the meaning of academic burnout can be made clear 
by comparing enthusiasm with boredom. Burnout is the opposite of enthusiasm, which is a high level of energy and commitment, a positive emotional state. Burnout is similar to boredom as an emotional state that results in lowered interest in activity and decreased concentration. In general, students with enthusiasm are more autonomous and accountable, whereas those who experience boredom are more likely to be stressed out and depressed. In this respect, academic burnout is a phenomenon in which students experience emotional exhaustion, cynicism, meaninglessness, and incompetence in their academic performance (Salmera-Aro 2017; Salmela-Aro, Kiuru, Leskinen, and Nurmi 2009; Salmela-Aro, Savolainen, and Holopainen 2009; Sulea, et al. 2015; Walburg 2014).

Despite the existence of only a few surveys, it is possible to estimate the relationship between growth mindset and academic burnout (Blackwell, Trzesniewski and Dweck 2007; Burnette, O’Boyle, Van Epps, Pollack, and Finkel 2013; Dweck 2009). While academic burnout is known to have a positive relationship with negative psychological variables such as perfectionism (Shih 2012) and anxiety (Silvar 2001), it shows negative relationships with positive emotional variables such as resilience (Jung and Kim 2016), self-control (Seibert, May, Fitzgerald, and Fincham 2016), self-efficacy (Bilge, Dost, and Cetin 2014), and academic engagement (Bilge and Dost 2014; Lee and Cho 2013; Tuominen-Soini and Salmela-Aro 2014).

It may be clear that fixed mindset can amplify and worsen academic burnout because such students are more likely to exacerbate burnout when exhausted by study and their passion or willingness cool. However, their growth mindset may decrease and even overcome academic burnout because it is possible that their belief in their academic aptitude and performance is maintained, and their willingness to be successful through their effort can persist.

Academic grit is a term used by Korean scholars to apply a concept of grit to academic situations. Grit, which was proposed by Duckworth, refers to a psychological state and power to maintain passionate interests and persistent effort by constantly striving to overcome the failures and frustrations they may experience in the job or learning performance (Duckworth 2016; Duckworth and Quinn 2009). Academic grit may be seen as a force that maintains enthusiastic motivation and persistent effort in order to arrive at academic goals and success (Lim 2017a). Lim and Cho (2018) indicated academic grit as comprising three sub-variables: academic enthusiasm, which is passionate and challenging to achieve academic goals; academic interest, which does not lose academic interest in the long-term course of academic performance; and academic persistence, which overcomes the difficulties and slumps experienced in the course of one's academic career (Credé, Tynan, and Harms 2017; Perkins-Gough 2013; Tough 2012; Vaino and Daukantaitè 2016).
Scholars distinguish between growth mindset and academic grit. Growth mindset focuses on "a positive belief or way of thinking" that if a student makes academic effort, academic performance can be improved without regard for their academic aptitude or intelligence. On the other hand, academic grit indicates "an action and effort" to engage in academic performance with unyielding will and enthusiasm for academic success even if it requires a great deal of time and effort in accomplishing a successful academic goal, or even if they encounter difficulties and obstacles (Duckworth, Peterson, Matthews, and Kelly 2007; Lim 2017a; Sanguras 2017).

Academic grit has been shown to have a statistically positive influence on academic performance and achievement (Lim 2017b), engagement (Tang, Wang, Guo, and Salmela-Aro 2019), growth mindset (Hodge, Wright, and Bennette 2018; Zhao, Niu, Hou, Zeng, Xu, Peng, and Yu 2018), resilience (Yeager and Dweck 2012), and psychological capital (Luthans, Luthans, and Chaffin 2019). Academic grit may play a role in reducing academic burnout while promoting an optimistic growth expectation among students by maintaining interest and effort for a long period of time even if there is a belief that learning is not fun or meaningful (Duckworth and Eskreis-Winkler 2013; Lim 2017a). A major difficulty in investigating whether academic grit plays a mediating role in the effect of growth mindset on academic burnout is a dearth of previous research. Extant prior studies found positive associations between grit and growth mindset in that the latter may contribute to a student's propensity for goal commitment and sustained effort (Bashant 2014; Molden and Dweck 2006; Perkins-Gough 2013; Wolters and Hussain 2015). It is possible to estimate that a growth mindset can reduce academic burnout owing to the mediating role of academic grit.

This study explored the mediating role of academic grit in the impact of growth mindset on academic burnout as perceived by Korean high school students. This theoretical model has not been investigated prior to this current study because little empirical research in this field has examined the correlation of growth mindset to academic burnout and a mediating role in the relationship. The research model and hypothesis are as follows.

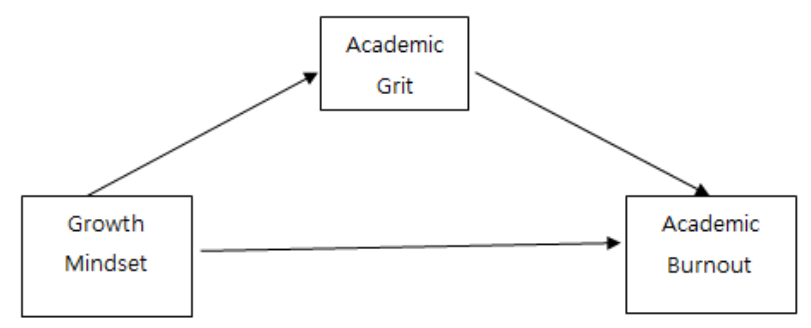

Figure 1. Research Model

Hypothesis 1: A growth mindset may lessen or relieve academic burnout.

Hypothesis 2: Academic grit will play a mediating role 
in reducing the effect of growth mindset on academic burnout.

\section{Method}

\subsection{Research Design and Sampling}

This study employed a correlational design to determine the degree to which a relationship exists between two or more variables and accordingly use either a research question or hypothesis by using statistical techniques such as correlation analysis (Fraenkel, Wallen, and Hyun 1993; Wood and Brink 1998). The author investigated the mediating effect of academic grit on the influence of growth mindset on academic burnout. This study applied convenience sampling and utilized data from members of the target population who met certain practical criteria, such as easy accessibility, geographical proximity, availability at a given time, or willingness to participate (Etikan, Musa, and Alkassim 2016; Farrokhi and Mahmoudi-Hamidabad 2012).

The sample of this study comprised 600 Korean high school students in Daegu Metropolitan, Korea in 2018. Each student who consented to the survey took approximately 20 minutes to complete the questionnaires. The responses of the 561 participants were analyzed as the final dataset. All these students were 17 years old. Of these students, 284 were male $(50.6 \%)$ and 277 were female (49.4\%). A majority (446) attended public school, whereas the remainder (115) attended private school. A smaller majority (397) participated in additional private cram school or other tutoring, and 164 students did not. Three hundred seventy-seven students (67.2\%) had made a firm decision to pursue either a college major or a job after high school graduation; 184 students (32.8\%) were in the undecided group.

\subsection{Measures}

The measures formulated in this study utilized questionnaires that had been validated in original research. It is possible that there is a limitation in assuring the accuracy and objectivity of a measurement because the measures involve the subjective perceptions or beliefs of participants about measured variables rather than objectively measure the abilities relating to growth mindset, academic grit, and academic burnout. The questionnaires utilized as measures in this study are as follows.

Growth mindset was measured using a Korean self-report scale validated by Lee (2015). There are 3 items ( $\alpha=.88,3$ items, e.g., "I can change my intelligence through the effort"). Cronbach's alpha $(\alpha)$ in this study was .90 for growth mindset.

Academic grit was measured a Korean self-report instrument validated by Lim and Cho (2018). There are 23 items in three sub-variables: academic enthusiasm ( $\alpha=.95$, 10 items, e.g., "I am full of passion when I study"), academic endurance ( $\alpha=.92,6$ items, e.g., "I am studying steadily"), and maintenance of academic interest ( $\alpha=.86,7$ items, e.g., "I keep my interest in study steady"). Cronbach's $\alpha$ of the sub-variables in this study were academic enthusiasm ( $\alpha=.96)$, academic endurance ( $\alpha$ $=.95)$, and maintenance of academic interest $(\alpha=.87)$, indicating high reliability. The scales used a 5-point Likert format ( 1 = strongly disagree and 5 = strongly agree).

Academic burnout was measured a Korean self-report instrument validated by Lee, Lee, and Lee (2009). There are 25 items in five sub-variables: exhaustion $(\alpha=.90,5$ items, e.g., "I feel exhausted from studying”), incompetence ( $\alpha=.89,5$ items, e.g., "I do not have the ability to study"), antipathy ( $\alpha=.89,5$ items, e.g., "I want to live in a world without study"), cynicism ( $\alpha=.86,5$ items, e.g., "I am skeptical that study will help in the future"), and anxiety ( $\alpha=.84,5$ items, e.g., "I am always worried when I study"). The scales used a 5-point Likert format $(1=$ strongly disagree and $5=$ strongly agree $)$. Cronbach's $\alpha$ of the sub-variables in this study were exhaustion $(\alpha=.88)$, incompetence ( $\alpha=.91)$, antipathy ( $\alpha$ $=.90)$, cynicism $(\alpha=.88)$ and anxiety $(\alpha=.87)$, indicating high reliability.

\subsection{Data Analysis}

Data analysis for this study yielded the kurtosis and skewness to verify the normality of the data, and Cronbach's $\alpha$ to verify the reliability of the scales used in this study. A correlation analysis of the data explored the relationship between variables by using SPSS 24 . This study also analyzed the mediating role of academic grit in the relationship between mindset and academic burnout by conducting structural equation modelling by using AMOS 24.

\section{Results}

\subsection{Descriptive Statistics and Correlations}

The assessment of whether a distribution is normal or not depends on its skewness and kurtosis values. According to Kline (2005), if the absolute value of kurtosis is greater than 10 and the absolute value of skew is greater than 3 , it is judged to be in violation of normal distribution. Table 2 shows the data used in this study were found to be within the normal range of skewness $(-.25-.22)$ and kurtosis $(-.50-.44)$ in all observed variables. Table 1 shows the results of the correlation between the variables used in this study. Overall, there was a statistically significant correlation between the observed variables at a significance level of 0.01 . As a result of the correlation between the variables, there was no multicollinearity, which would have indicated a highly linear relationship, among the measured values with a high correlation of 0.85 or more (Kline 2005). 
Table 1. Correlations between the measured variables

\begin{tabular}{|c|c|c|c|c|c|c|c|c|c|c|c|c|c|c|}
\hline \multicolumn{2}{|l|}{ Variable } & $M$ & $S D$ & Skew & kurtosis & (1) & (2) & (3) & (4) & (5) & (6) & (7) & (8) & (9) \\
\hline Growth Mindset & (1) & 3.90 & 1.02 & -.10 & .37 & 1 & & & & & & & & \\
\hline \multirow{3}{*}{$\begin{array}{c}\text { Academic } \\
\text { Grit }\end{array}$} & (2) & 3.07 & .84 & -.02 & .37 & $.36^{* *}$ & 1 & & & & & & & \\
\hline & (3) & 2.97 & .85 & .15 & .24 & $.28^{* *}$ & $.78^{* *}$ & 1 & & & & & & \\
\hline & (4) & 2.72 & .80 & .22 & .44 & $.34^{* *}$ & $.70^{* * *}$ & $.70^{* *}$ & 1 & & & & & \\
\hline \multirow{5}{*}{$\begin{array}{c}\text { Academic } \\
\text { Burnout }\end{array}$} & (5) & 2.72 & .96 & .14 & -.32 & $-.24^{* *}$ & $-.25^{* *}$ & $-.22^{* *}$ & $-.26^{* *}$ & 1 & & & & \\
\hline & (6) & 2.82 & .95 & .14 & -.33 & $-.20^{* *}$ & $-.42^{* *}$ & $-.38^{* *}$ & $-.35^{* *}$ & $.55^{* *}$ & 1 & & & \\
\hline & (7) & 3.02 & .92 & -.02 & -.26 & $-.11^{* *}$ & $-.10^{* *}$ & $-.09 *$ & $-.18^{* * *}$ & $.48^{* *}$ & $.50^{* *}$ & 1 & & \\
\hline & (8) & 2.90 & .98 & -.06 & -.50 & $-.10^{* *}$ & $.11^{* *}$ & .06 & -.02 & $.40^{* *}$ & $.35^{* *}$ & $.53^{* *}$ & 1 & \\
\hline & (9) & 3.37 & 1.00 & -.25 & -.42 & $-.22^{* *}$ & $-.35^{* *}$ & $-.34^{* *}$ & $-.43^{* *}$ & $.55^{* *}$ & $.66^{* *}$ & $.54^{* *}$ & $.37^{* *}$ & 1 \\
\hline
\end{tabular}

${ }^{* *} p<.01$.

Note. (1) growth mindset (2) academic enthusiasm (3) academic endurance (4) maintenance of academic interest (5) incompetence (6) antipathy (7) exhaustion (8) anxiety (9) cynicism

Table 2. Convergent validity of the measurement model

\begin{tabular}{|c|c|c|c|c|c|c|c|}
\hline $\begin{array}{c}\text { Latent } \\
\text { variable }\end{array}$ & $\begin{array}{l}\text { Measured } \\
\text { Variable }\end{array}$ & $\begin{array}{l}\text { Unstandardized } \\
\text { coefficients }\end{array}$ & $\begin{array}{l}\text { Standardized } \\
\text { coefficients }\end{array}$ & $\begin{array}{l}\text { Standard } \\
\text { error }\end{array}$ & t value & $\begin{array}{l}\text { Construct } \\
\text { reliability }\end{array}$ & AVE \\
\hline \multirow{3}{*}{$\begin{array}{l}\text { Growth } \\
\text { Mindset }\end{array}$} & Mindset1 & - & .87 & - & - & \multirow{3}{*}{.90} & \multirow{3}{*}{.74} \\
\hline & Mindset2 & 1.06 & .93 & .04 & $29.24^{* * *}$ & & \\
\hline & Mindset3 & .97 & .84 & .04 & $25.95^{* * *}$ & & \\
\hline \multirow{3}{*}{$\begin{array}{l}\text { Academic } \\
\text { Grit }\end{array}$} & Academic Enthusiasm & - & .89 & - & - & \multirow{3}{*}{.92} & \multirow{3}{*}{.80} \\
\hline & Academic Endurance & .99 & .87 & .04 & $25.68^{* * *}$ & & \\
\hline & $\begin{array}{c}\text { Maintenance of Academic } \\
\text { Interest }\end{array}$ & .85 & .80 & .04 & $23.01^{* * *}$ & & \\
\hline \multirow{5}{*}{$\begin{array}{l}\text { Academic } \\
\text { Burnout }\end{array}$} & Antipathy & - & .83 & - & - & \multirow{5}{*}{.82} & \multirow{5}{*}{.50} \\
\hline & Anxiety & .49 & .42 & .05 & $9.25^{* * *}$ & & \\
\hline & Exhaustion & .69 & .63 & .05 & $14.66^{* * *}$ & & \\
\hline & Cynicism & .93 & .81 & .05 & $18.91^{* * * *}$ & & \\
\hline & Incompetence & .79 & .68 & .05 & $16.14^{* * *}$ & & \\
\hline
\end{tabular}

${ }^{* * *} p<.001$

\subsection{Testing the Measurement Model}

The measurement model needed to confirm that the latent variables were represented by observed variables and then assess the hypothesized structural model. According to Kline (2005), several indexes were calculated to evaluate the fit of the model to the data: the chi-square $\left(\chi^{2} / d f<2.0\right.$ suggests a good fit), the comparative fit index (CFI $>0.90$ ), the Tucker-Lewis index (TLI $>0.90$ ), the goodness-of-fit index (GFI $>0.90)$, the root mean square error of approximation (RMSEA $<0.10$ ). The measurement model showed good fit statistics for the latent variables, $\chi^{2}(39)=193.17, p=0.001, \chi^{2} / d f=4.95$, GFI $=$ $0.94, \mathrm{CFI}=0.96, \mathrm{TLI}=0.94$ and $\mathrm{RMSEA}=0.08$.

Construct validity may be further assessed by calculating the convergent validity as a set of variables presumed to assess the same construct and the discriminant validity as a set of variables presumed to measure different constructs (Kline 2005). Construct validity was assessed by calculating convergent validity in establishing a measurement model. Convergent validity was assessed by the construct reliability and Average Variance Extracted (AVE) of the factors in the measurement model. Theoretically, if the construct reliability is 0.7 or more and AVE is 0.5 or more, the validity of the measurement model is satisfactory (Yu, 2012). Table 3 shows that all standardized loadings of the variables were significant ( $p<$ 0.001 ; range $0.42-0.95$ for each variable). As Table 2 shows, the construct reliability for each variable was 0.90 for growth mindset, 0.92 for academic grit, and 0.83 for academic burnout. In addition, AVE has a validity of the measurement model with growth mindset of 0.74 , academic grit of 0.80 , and academic burnout of 0.50 . In this regard, the construct validity of the measurement model was satisfactory. In terms of discriminant validity, if the AVE is greater than the squared correlation coefficient $(\varphi 2)$ between each latent factor at the bottom of the diagonal (Yu 2012), discriminant validity can be secured as Table 3 shows. 
Table 3. Discriminant validity

\begin{tabular}{|c|c|c|c|}
\hline Latent variable & Mindset & Academic Grit & Academic Burnout \\
\hline $\begin{array}{c}\text { Growth } \\
\text { Mindset }\end{array}$ & $.74^{*}$ & & \\
\hline Academic Grit & $.13 \mathrm{c}$ & $.80^{*}$ & \\
\hline $\begin{array}{c}\text { Academic } \\
\text { Burnout }\end{array}$ & $.05 \mathrm{c}$ & $.09 \mathrm{c}$ & $.50^{*}$ \\
\hline
\end{tabular}

$*=\mathrm{AVE}, \mathrm{c}=\varphi 2$ (squared correlation coefficient between latent variable), acceptance criteria: A.V.E $>\varphi 2$

\subsection{Testing the Structural Model}

In order to assess the fit of the structural model to the data, the following indexes were calculated: chi-square $\left(\chi^{2} / d f<2.0\right.$ suggests a good fit), the comparative fit index (CFI > 0.90), the Tucker-Lewis index (TLI > 0.90), the goodness-of-fit index (GFI > 0.90), the root mean square error of approximation (RMSEA $<.10)$. The structural model showed good fit statistics for the latent variables, $\chi^{2}$ $(39)=193.17, p=0.001, \chi^{2} / d f=4.95$, GFI $=0.94$, CFI $=$ 0.96 , TLI $=0.94$, and RMSEA $=0.08$. Table 4 shows that the direct path coefficient from growth mindset to academic grit was significant $(\beta=.40, p<.001)$, the direct path coefficient from academic grit to academic burnout was significant $(\beta=-.43, p<.001)$, the direct path coefficient from growth mindset to academic burnout was significant $(\beta=-.11, p<.05)$.

The proportion of explained variance for the model presented by squared multiple correlations (SMC) was $16.0 \%$ for academic grit and $23.0 \%$ for academic burnout (Kline 2005). The direct and indirect effects between pathways were presented in Table 5 . In this study, the indirect effect of academic grit on the relationship between growth mindset and academic burnout is -.17, implying that the effect of growth mindset on academic burnout can be further reduced when academic grit mediates.

Bootstrapping was used to test the significance of the mediating effect as suggested by Shrout and Bolger (2002). The bootstrapping results show the 95\% confidence interval (CI) for the significance of mean indirect effect from the bootstrap results. If the CI does not include zero, then the indirect effect is considered statistically significant at the 0.05 level. Table 6 shows the results of bootstrapping analysis for the mediating role of academic grit in the relationship between growth mindset and academic burnout ( $\mathrm{b}=0.26,95 \% \mathrm{CI}$ : $0.18 \sim 0.32$ ) were significant, because zero is not included in the range.

Table 4. Coefficients of the structural model

\begin{tabular}{|c|c|c|c|c|}
\hline Path & $\begin{array}{c}\text { Unstandardized } \\
\text { estimate }\end{array}$ & $\begin{array}{c}\text { Standardized } \\
\text { estimate }\end{array}$ & $\begin{array}{c}\text { Standardized } \\
\text { errors }\end{array}$ & $t$ value \\
\hline Growth Mindset $\rightarrow$ Academic Grit & .26 & .40 & .03 & $8.60^{* * *}$ \\
\hline Academic Grit $\rightarrow$ Academic Burnout & -44 & -.43 & .06 & $-7.92^{* * *}$ \\
\hline Growth Mindset $\rightarrow$ Academic Burnout & -.07 & -.11 & .03 & $-2.24^{*}$ \\
\hline
\end{tabular}

${ }^{*} p<.05,{ }^{* * *} p<.001$.

Table 5. Effect decomposition of the structural model

\begin{tabular}{|c|c|c|c|c|c|}
\hline Independent variable & Dependent variable & Direct effect & Indirect effect & Total effect & $S M C\left(R^{2}\right)$ \\
\hline Growth Mindset & Academic Grit & .40 & - & .40 & .16 \\
\hline Academic Grit & Academic Burnout & -.43 & - & -.43 & .23 \\
\hline Growth Mindset & Academic Burnout & -.11 & -.17 & -.28 \\
\hline
\end{tabular}

Table 6. Bootstrapping analysis for the mediating effect test

\begin{tabular}{|c|c|c|}
\hline Pathway & Unstandardized (b) & S.E. \\
\hline Growth Mindset $\rightarrow$ Academic Grit $\rightarrow$ Academic Burnout & .26 & $.03 \%$ CI \\
\hline
\end{tabular}

${ }^{*} p<.05$. 


\section{Discussion}

This study explored the mediating role of academic grit in the impact of growth mindset on academic burnout as perceived by Korean high school students. It found that growth mindset may have a negative influence on academic burnout. This study supported Hypothesis 1 in that growth mindset may lessen or relieve academic burnout. It is significant that students with growth mindset who have strong self-confidence and optimistic view toward improving their academic achievement are less likely to experience academic burnout. Due to an overall lack of research, it is not easy to validate empirically the impact of growth mindset on academic burnout; however, it is possible to estimate this result on the basis of relevant prior studies. Growth mindset lessens or prevents academic burnout because students who have growth mindset have the academic performance goal and the self-regulation or resilience of academic boredom and exhaustion (Bashant 2014; Dweck, Walton, and Cohen 2014; Sanguras 2017; Yeagers and Dweck 2012; Zeng, Hou, and Peng 2016). In this respect, growth mindset may act as a preventive or diminishing factor for academic burnout.

This study did support Hypothesis 2 concerning academic grit's mediation of the effect of growth mindset on academic burnout. It found that academic grit plays a mediating role in further lowering the effect of growth mindset on academic burnout. In spite of scarce prior research, it is possible to conjecture that students exhibiting growth mindset can lessen or relieve their academic burnout by recovering lowered vigor in their performance, by holding more optimistic expectations of their outcomes, and by making more persistent effort through exerting their academic grit (Burnette, O’Boyle, Van Epps, Pollack, and Finkel 2013; Duckworth and Eskreis-Winkler 2013; Hodge, Wright, and Bennette 2018; Tang, Wang, Guo, and Salmela-Aro 2019; Zhao, Niu, Hou, Zeng, Xu, Peng, and Yu 2018). In this respect, academic grit may play a further diminished or lessened role in the effect of growth mindset on relieving academic burnout.

The results of this study can be used by teachers in considering and adopting instruction and guidance strategies in their classrooms to prevent academic burnout by improving growth mindset and academic grit. This study presents four strategies that teachers may apply in the classroom. First, teachers should give positive feedback or praise of effort that is focused on students' academic performance as well as urge their students to put forth a positive self-dialogue of "I can do it." Doing so will help students to develop academic optimism and positive self-image (Syed 2018; Ricci 2015).

Second, teachers should recommend students to overcome "academic dip or slump" by setting up a learning habit that allows them to continue their studies regularly for two to three hours each day (Meadows 2015, p. 8). Academic dip means the periods which leave students feeling stuck or slow in their learning progress after they experienced rapid growth enjoyed at the beginning of their learning. In the course of experiencing academic dip, students who continue to work tirelessly may witness their academic performance accelerate again and lead to high achievement; grit is what such students need. Teachers need to advise their students that if they study for two or three hours a day, they will experience a successful academic performance after a tough and tedious academic dip.

Third, Dweck (2006) argues that students who show growth mindset are likely to have mastery goals that they establish to accept the challenge of and successfully complete their academic tasks rather than performance goals established to demonstrate better or higher achievement in comparison with other students. In this respect, teachers should provide students with challenging but achievable goals that enable them to complete their own academic tasks and become satisfied with incremental academic achievements in daily school life (Sanguras 2017).

Fourth, teachers can present students with celebrities or legends as models such as NBA superstar Michael Jordan or Apple co-founder and former CEO Steve Jobs, whose passionate and persistent practice toward achieving their goals contributed to their great success. To this end, teachers can show or recommend books, movies, YouTube clips, and other media sources (Polirstok 2017). Also, drawing examples to celebrities who have achieved outstanding success with persistence and effort, teachers can introduce their peers or graduates who have recently attained high academic achievements by overcoming a recent learning dip or slump and can use them as peer mentors in their classroom by collaborating with the students (Dweck, Walton, and Cohen 2014).

The academic significance of this present study consists in providing a theoretical and empirical basis for investigating the relationship among mindset, academic grit, and academic burnout owing to the lack of previous studies. That is, the study's structural model demonstrates that having growth mindset predicts a higher degree of academic grit, which in turn reduces academic burnout. It is especially significant in identifying that academic grit can play a mediating role in lowering or preventing academic burnout when a student exerts herself or himself with a growth mindset.

However, this study's suggestions for future research must be viewed in the light of the limitations in this study. First, because this study is cross-sectional, the structural relationship is insufficient for exploring any causal relationship that may exist among growth mindset, academic grit, and academic burnout. It is vital to conduct further experimental and longitudinal studies to identify causal relationships among the present research variables or the related various variables such as engagement, 
self-regulation, and resilience. Second, this study is limited by the fact that it does not take into account variables such as students' demographic backgrounds, classroom climate and contexts, and teachers' leadership and interest in their students. Such variables may affect the relationship of growth mindset, academic grit, and academic burnout. Therefore, it is necessary for future studies to use experimental and quasi-experimental research to verify the effects of academic grit on academic burnout under various learning conditions and contexts of learners' individual learning and task performance in their tutoring or clam school. Third, it is needed to use a multilevel model or a hierarchical linear model in order to identify individual characteristics and organizational characteristics. Fourth, it may be difficult to generalize the results applied to Korean high school students outside Korea; therefore, it is necessary to identify criteria for generalizing this study by administering a survey to students elsewhere in East Asia, such as Japan, Taiwan, and China.

In conclusion, this study found that growth mindset may act as a diminishing factor for academic burnout. In addition, this study found that academic grit negatively mediated the relationship between growth mindset and academic burnout, implying that academic grit can play a determinant role as a positive psychological variable that could alleviate or prevent academic burnout. Therefore, a school needs to develop and provide their students with programs and counseling that can foster academic grit in order to lessen or prevent academic burnout.

\section{REFERENCES}

[1] Bilge, F., Dost, M. T., \& Çetin, B. (2014). Factors affecting burnout and school engagement among high school students: Study habits, self-efficacy beliefs, and academic success. Educational Science: Theory and Practices, 14(5), 1721-1727.

[2] Blackwell, L. S., Trzesniewski, K. H., \& Dweck, C. S. (2007). Implicit theories of intelligence predict achievement across an adolescent transition: A longitudinal study and an intervention. Child Development, 78(1), 246-263.

[3] Burnette, J. L., O’Boyle, E., Van Epps, E. M., Pollack, J. M., \& Finkel, E. J. (2013). Mindsets matter: A metaanalytic review of implicit theories and self-regulation. Psychological Bulletin, 139(3), 655-701.

[4] Credé, M., Tynan, M. C., \& Harms, P. D. (2017). Much ado about grit: A meta-analytic synthesis of the grit literature. Journal of Personality and Social Psychology, 113(3), 492.

[5] Duckworth, A. L., \& Eskreis-Winkler, L. (2013). Grit. Observer, 26(4), 1-3.

[6] Duckworth, A. L., \& Quinn, P. D. (2009). Development and validation of the Short Grit Scale (GRIT-S). Journal of Personality Assessment, 91(2), 166-174.

[7] Duckworth, A. L., Peterson, C., Matthews, M. D., \& Kelly,
D. R. (2007). Grit: Perseverance and passion for long-term goals. Journal of Personality and Social Psychology, 92(6), 1087-1101.

[8] Duckworth, A. L. (2016). Grit: The power of passion and perseverance. New York: Scribner.

[9] Dweck, C. S. (2006). Mindset: The new psychology of success. New York: Random House.

[10] Dweck, C. S. (2009). Mindsets: Developing talent through a growth mindset. Olympic Coach, 21(1), 4-7.

[11] Dweck, C. S., Walton, G. M., \& Cohen, G. L. (2014). Academic tenacity: Mindsets and skills that promote long-term learning. Retrieved November 11, 2019 from www.gatesfoundation.org

[12] Etikan, I., Musa, S. A., \& Alkassim, R. S. (2016). Comparison of convenience sampling and purposive sampling. American Journal of Theoretical and Applied Statistics, 5(1), 1-4.

[13] Farrokhi, F., \& Mahmoudi-Hamidabad, A. (2012) Rethinking convenience sampling: Defining quality criteria. Theory and Practice in Language Studies, 2(4), 784.

[14] Fraenkel, J. R., Wallen, N. E., \& Hyun, H. H. (1993). How to design and evaluate research in education (Vol. 7), New York: McGraw-Hill.

[15] Hochanadel, A., \& Finamore, D. (2015). Fixed and growth mindset in education and how grit helps students persist in the face of adversity. Journal of International Education Research, 11(1), 47-50.

[16] Hodge, B., Wright, B., \& Bennett, P. (2018). The role of grit in determining engagement and academic outcomes for university students. Research in Higher Education, 59(4), 448-460.

[17] Jung, I. K., \& Kim, J. H. (2016). The moderating effects of stress coping strategies on the relationship between academic self-efficacy and academic burnout in adolescents. Korean Education Inquiry, 34(4), 193-211.

[18] Kline, R. B. (2005). Principles and practice of structural equation modeling (2nd ed.), New York: Guilford Press.

[19] Lee, J. L. (2015). An analysis of structural relationship among locus of control, mindset, grit, and academic achievement, Unpublished Dissertation, Andong University.

[20] Lee, H. A., \& Cho, H. I. (2013). The relation among perfectionism, academic engagement and academic burnout: The mediating effects of motives and goal processes. Korean Journal of Counseling and Psychotherapy, Vol. 25 No. 3, pp. 575-601.

[21] Lee, S. J., \& Shin, T. S. (2018). The effects of mindsets on academic self-efficacy of high school students mediated by grit: Multi-group analysis according to whether the students gave up on mathematics or not”, Asian Journal of Education, Vol. 19 No. 3, pp. 59-87.

[22] Lee, Y. B., Lee, S. M., \& Lee, J. Y. (2009), "Development of Korean academic burnout scale”, The Korea Educational Review, Vol. 15 No. 3, pp. 59-78.

[23] Lim, H. H., \& Cho, H. I. (2018). The development and 
validation of an academic grit scale for adolescents. The Korean Journal of Educational Psychology, 32(3), 495-523.

[24] Lim, H. J. (2017a). An exploratory study on Grit's factor structure and its validity. Asian Journal of Education, 18(2), 169-192.

[25] Lim, H. J. (2017b). A structural relationship among grit, creative disposition, and creative thinking. The Journal of Thinking Development, 13(2), 45-65.

[26] Lim, H. J. (2018). The structural relationship among grit, intrinsic-extrinsic value, classroom engagement, cognitive regulation, and academic achievement. The SNU Journal of Education Research, 27(3), 235-256.

[27] Luthans, K. W., Luthans, B. C., \& Chaffin, T. D. (2019). Refining grit in academic performance: The mediational role of psychological capital. Journal of Management Education, 43(1), 35-61.

[28] McClendon, C., Neugebauer, R. M., \& King, A. (2017). Grit, growth mindset, and deliberate practice in online learning. Journal of Instructional Research, 6, 8-17.

[29] Meadows, M. (2015). Grit: How to keep going when you want to give up. Schaumburg, IL: Meadows Publishing.

[30] Molden, D. C., \& Dweck, C. S. (2006). Finding “meaning” in psychology: A lay theories approach to self-regulation, social perception, and social development. American Psychologist, 61, 192-203.

[31] OECD (2014), PISA 2012 results (Volume III): Ready to learn: Students' engagement, drive and self-beliefs, Paris: OECD.

[32] OECD. (2017), PISA 2015 results (Volume III): Students' well-being, Paris: OECD.

[33] OECD. (2017), PISA 2015 results (Volume I): Excellence and equity in education, Paris: OECD.

[34] OECD. (2018), Education at a Glance 2018: OECD Indicators, Paris: OECD.

[35] Polirstok, S. (2017). Strategies to improve academic achievement in secondary school students: Perspectives on grit and mindset. Sage Open, 7(4), 1-9.

[36] Perkins-Gough, D. (2013). The significance of GRIT: a conversation with Angela Lee Duckworth. Educational Leadership, 71(1), 14-20.

[37] Ricci, M. C. (2015). Ready-to-use resources for mindsets in the classroom: Everything educators need for building growth mindset learning communities. Waco, TX: Prufrock Press.

[38] Salmela-Aro, K. (2017). Dark and bright sides of thrivingschool burnout and engagement in the Finnish context. European Journal of Developmental Psychology, 14(3), 337-349.

[39] Salmela-Aro, K., Kiuru, N., Leskinen, E., \& Nurmi, J. (2009). School Burnout Inventory (SBI) reliability and validity. European Journal of Psychological Assessment, $25,48-57$.

[40] Salmela-Aro, K., Savolainen, H., \& Holopainen, L. (2009).
Depressive symptoms and school burnout during adolescence: Evidence from two cross-lagged longitudinal studies. Journal of Youth and Adolescence, 38(10), 13161327.

[41] Sanguras, L. Y. (2017). Grit in the classroom: Building perseverance for excellence in today's students. Waco, TX: Purfrock Press.

[42] Seibert, G. S., May, R. W., Fitzgerald, M. C., \& Fincham, F. D. (2016). Understanding school burnout: Does self-control matter? Learning and Individual Differences, 49, 120-127.

[43] Shih, S. S. (2012). An examination of academic burnout versus work engagement among Taiwanese adolescents, The Journal of Educational Research, 105, 286-298.

[44] Shrout, P. E., \& Bolger, N. (2002). Mediation in experimental and nonexperimental studies: New procedures and recommendations, Psychological Methods, 7, 422-445.

[45] Silvar, B. (2001). The syndrome of burnout, self-image, and anxiety with grammar school students. Horizons of Psychology, 10, 21-32.

[46] Suh, M. O. (2018). A meta-analysis on the relationships between academic burnout and related variables among secondary school students. The Korean Journal of Educational Psychology, 32(1), 53-78.

[47] Sulea, C., Beek, I. V., Sarbescu, P., Virga, D., \& Schaufeli, W. B. (2015). Engagement, boredom, and burnout among students: Basic need satisfaction matters more than personality traits, Learning and Individual Differences, 42, $132-138$.

[48] Syed, M. (2018). You are awesome: Find your confidence and dare to be brilliant at (almost) anything. London: Wren \& Rook.

[49] Tang, X., Wang, M. T., Guo, J., \& Salmela-Aro, K. (2019). Building grit: The longitudinal pathways between mindset, commitment, grit, and academic outcomes. Journal of Youth and Adolescence, 48(5), 850-863.

[50] The Korea Statistical Office (2018), Adolescents statistics, http://www.kostat.go.kr/.

[51] Tough, P. (2012), How children succeed: Grit, curiosity, and the hidden power of character, Boston, MA: Houghton Mifflin Harcourt.

[52] Tuominen-Soini, H., \& Salmela-Aro, K. (2014). Schoolwork engagement and burnout among Finnish high school students and young adults: Profiles, progressions, and educational outcomes. Developmental psychology, 50(3), 649-662.

[53] Vainio, M. M., \& Daukantaitè, D. (2016). Grit and different aspects of well-being: Direct and indirect relationships via sense of coherence and authenticity. Journal of Happiness Studies, 17(5), 2119-2147.

[54] Walburg, V. (2014). Burnout among high school students: A literature review. Children and Youth Services Review, 42, 28-33.

[55] Wolters, C. A., \& Hussain, M. (2015), Investigating grit and its relations with college students' self-regulated learning and academic achievement. Metacognition and Learning, 10(3), 293-311. 
[56] Wood, M. J., \& Brink, P. J. (1998), Correlational designs: Advanced design in nursing research (2nd ed.), Thousand Oaks, CA: Sage Publications.

[57] Yeager, D. S., \& Dweck, C. S. (2012). Mindsets that promote resilience: When students believe that personal characteristics can be developed. Educational Psychologist, 47(4), 302-314.

[58] Yu, J. P. (2012), Concepts and understanding of structural equation modeling, Seoul: Hannare.
[59] Zhao, Y., Niu, G., Hou, H., Zeng, G., Xu, L., Peng, K., \& Yu, F. (2018). From growth mindset to grit in Chinese schools: The mediating roles of learning motivations. Frontiers in Psychology, 9(2007), 1-7.

[60] Zeng, G., Hou, H., \& Peng, K. (2016). Effect of growth mindset on school engagement and psychological well-being of Chinese primary and middle school students: The mediating role of resilience. Frontiers in Psychology, 7(1873), 1-8. 